\title{
LIBERTOS E ESCRAVOS NO CONTEXTO MILITAR DO INÍCIO DO PERÍODO IMPERIAL, PROVÍNCIA DE SANTA CATARINA
}

\author{
FREEDMEN AND SLAVES IN THE MILITARY CONTEXT OF THE \\ BEGINNING OF THE IMPERIAL PERIOD, PROVINCE OF SANTA \\ CATARINA
}

\begin{abstract}
Ânderson Marcelo Schmitt ${ }^{1}$
RESUMO: O presente artigo discute a presença de homens considerados "de cor" nas forças armadas no início do período imperial brasileiro, a partir do caso da província de Santa Catarina. As categorias utilizadas para definir a cor dos sujeitos e classificá-los por hierarquias sociais eram relevantes quando se pensava a criação e manutenção de corpos militares. Argumenta-se que as forças armadas, e os períodos de conflito, em especial, aumentavam as possibilidades para que libertos ou escravos buscassem ampliar seu grau de liberdade. Partindo dos parâmetros da Nova História Militar, utiliza-se documentação trocada entre as autoridades responsáveis por pensar o recrutamento.

ABSTRACT: This article discusses the presence of men considered "colored" in the army at the beginning of the Brazilian imperial period, from the case of the province of Santa Catarina. The categories used to define the peoples' color and classify them by social hierarchies were relevant when thinking about the creation and maintenance of military corps. It is argued that the armed forces, and periods of conflict, in particular, increased the possibilities for freedmen or slaves to seek to expand their degree of freedom. Following the parameters of the New Military History, this article uses the documentation exchanged between the authorities responsible for thinking about the recruitment.
\end{abstract}

KEYWORDS: Slavery; Independence; Freedom; Militarization.

\footnotetext{
* Esta pesquisa contou com apoio financeiro do CNPq.

1 Doutorando em História (Universidade Federal de Santa Catarina, UFSC). E-mail: anderschm@gmail.com. ORCID: https://orcid.org/0000-0002-6245-277X.
} 


\section{Introdução}

Neste artigo, analisa-se a participação de libertos e/ou escravos nas forças armadas brasileiras no início do período imperial, na província de Santa Catarina. As idiossincrasias da formação e utilização do exército luso-brasileiro vem sendo analisadas por inúmeros historiadores atentos às inerências entre a sociedade e as instituições (para-)militares, na corrente chamada de Nova História Militar (NOGUEIRA, 2009; RIBEIRO, 2013; MENDES, 2010; MUGGE, 2012). Para além destas análises, outros estudos abordam a questão da relação racial dentro das forças armadas, não deixando de frisar que o exército - e os momentos de conflitos em especial - devem ser interpretados com sua potencialidade para a criação de estratégias ${ }^{2}$ por parte de atores sociais que podem parecer, em um primeiro momento, desprovidos de agência (IZECKSOHN, 2014; KRAAY, 2015; BEATTIE, 2009; CARVALHO, 2013; ALADRÉN, 2012). Para o objetivo proposto, foi consultada a documentação contemporânea ao período, principalmente os ofícios enviados pela Junta Governativa Provisória e presidentes da província de Santa Catarina ao Comandante/Governador das Armas, autoridade responsável em nível provincial, no início do período imperial, por gerir a organização do exército ${ }^{3}$. Este tipo de documento permite verificar as deliberações que estavam sendo tomadas em momentos específicos, sendo necessário, portanto, compreensão do contexto político-militar brasileiro, cruzando informações, quando possível, com outras províncias brasileiras. Além disso, são muito raras ocasiões em que a documentação de caráter militar traz a versão dos fatos contadas pelos próprios soldados rasos (RIBEIRO, 2012, p. 157), forçando o historiador militar a depender dos fatos e da lógica para buscar a "estrutura da explicação histórica" (THOMPSOM, 1987, p. 143).

\footnotetext{
${ }^{2}$ Faz-se uso de "estratégia" ligada à racionalidade, sendo empregada, no dizer de Levi, "na obra de transformação e utilização do mundo social e natural" (2000, p. 45).

${ }^{3}$ O cargo de Comandante ou Governador das Armas foi instituído em 1821, durante o movimento liberal português. Possuíam independência do poder Executivo provincial, respondendo diretamente a Lisboa. Em 1823, pós-independência, tiveram suas atribuições limitadas, devendo suas decisões ser aprovadas pelos presidentes provinciais (SLEMIAN, 2006b, p. 112). O posto existiu até 1831.
} 
O ano de 1822 marcou a ruptura político-institucional da América portuguesa, cujo caráter já havia sido modificado em 1815, com a criação do Reino Unido de Portugal, Brasil e Algarves. Este processo de independência dos domínios lusos teve início ainda em 1807/8, quando da partida e chegada da família real bragantina em direção a suas posses na América. Foram os movimentos políticos ligados às ideias ilustradas que forçaram os Bragança a deixar Portugal e rumar para a América do Sul. Contraditoriamente, foram as mesmas idéias que tornaram inevitáveis as exigências do retorno dos líderes lusos. Dom João VI se viu obrigado a voltar a Portugal em 1821, na esteira da chamada regeneração vintista, por exigências das cortes, que prometiam, para além da elaboração de uma Constituição (NEVES, 2011, p. 115), a destituição total dos poderes do monarca, caso não houvesse um pronto retorno.

Os desencadeamentos políticos do processo de independência consumado em 1822 não trouxeram imediatas mudanças estruturais para uma sociedade fortemente baseada sobre a mão de obra escrava, não obstante as inúmeras atividades econômicas que poderiam ser encontradas nas mais diversas partes do Brasil. No Império brasileiro, o liberalismo que emanou do velho continente se demonstrou conservador nas questões de ordem política, social e escravista, ao mesmo tempo em que embasou uma "construção constitucional da cidadania", trazendo "novidades circunscritas a um projeto normativo liberal" (SLEMIAN, 2006, p. 847). As promessas constitucionais, que já estavam em voga desde os trabalhos das cortes portuguesas, deixavam vislumbrar aos atores sociais uma possível modificação de seu status dentro da sociedade luso-brasileira. Em suma, o período da independência ficou marcado pelas "expectativas entretidas por diversos setores da população a respeito das transformações políticas em curso" (MAMIGONIAN, 2017, p. 52).

A manutenção da escravidão na Constituição de 1824 não chegou a ser uma surpresa, condizente com o liberalismo conservador do ponto de vista social. Em sentido oposto, as discussões da Assembleia Constituinte em 1823 que em grande medida foram outorgadas em 1824 - não colocaram barreiras ligadas à cor da pele ou condicionaram à pureza de sangue o acesso à cidadania, 
muito menos barraram esta possibilidade a ex-escravos. Assim, os próprios cativos podiam enxergar a possibilidade de, com a alforria, adquirem direitos civis e até mesmo políticos (SLEMIAN, 2016).

O liberalismo excludente que vigorou no Brasil imperial (GRINBERG, 2002), foi além de uma questão unicamente brasileira. É necessário frisar, como lembrado por Hebe Mattos, "que o conhecido dilema entre a assertiva de que os homens nasciam livres e iguais reconhecida pelo liberalismo e a manutenção da escravidão, sob a égide de Constituições liberais, não foi específico do Brasil de 1822", mas sim, teve espaço "em toda a Afro-América, inclusive nas colônias escravistas inglesas e francesas, no contexto das chamadas Revoluções Atlânticas" (2000, p 7-8). Sendo assim, as guerras que decorreram dos diversos processos de emancipação na América foram aproveitadas por escravos ou libertos em busca de melhores condições, ou mesmo foram usadas como canais para forçar o reconhecimento de direitos imediatos ou vindouros (SCOTT, 2006; MORELLI, 2018; RODRÍGUES, 2005). Como recentemente apontou Federica Morelli, negros e pardos livres desempenharam, nos movimentos armados de independência da América, um papel importante, influenciando o debate político sobre cidadania, e forçando as elites a anuir a medidas radicais não pensadas inicialmente (MORELLI, 2018, p. 152-154). Assim, estes grupos subalternos usavam o ato de pegar em armas para aumentar seu horizonte de possibilidades. Deste modo, o recorte temporal deste artigo vai desde a independência formal em 1822, e perpassa a Guerra da Cisplatina (1825-1828), representando momentos de agitação política e militar marcado pelo surgimento dos estados sul-americanos.

O cenário deste artigo - a capitania/província - de Santa Catarina, foi entreposto nas diversas vezes em que os portugueses estiveram em litígio com os vizinhos espanhóis no sul da colônia. Por si só, a Ilha de Santa Catarina (atual Florianópolis) era visada por sua localização estratégica e bons portos que permitiam aguada e repouso para as tripulações. Por outro lado, a intromissão portuguesa no território se deu por terra a partir de São Vicente. Ainda durante o século XVII, teve início um processo em que famílias - ou 
parte delas -, inicialmente atraídas pelo aprisionamento de indígenas e gado da campanha sulina, foram se transferindo para a região próxima ao litoral da futura capitania catarinense (CARDOSO, 2013; KÜHN, 2006). Não obstante a existência de grandes propriedades ligadas à pecuária principalmente na região de Laguna, no continente ao sul da Ilha, a pequena produção voltada ao mercado interno era predominante no início do século XIX. A agricultura, voltada à produção de farinha de mandioca, os engenhos de açúcar e a atividade de pesca de baleias marcaram as atividades econômicas da capitania, todas ligadas à mão de obra escrava. Segundo Gomes, a presença de escravos no total da população entre o último quartel do século XVIII e as três primeiras décadas do XIX se manteve entre 30 e $17 \%$ do total da população, variando entre os distritos desta província (2017, p. 606).

\section{O exército na independência}

Era 23 de outubro de 1822, e as implicações do processo da independência ainda ecoavam. Nesta data a Junta de Governo Provisória de Santa Catarina ${ }^{4}$ aprovou a atitude do Comandante das Armas, Aureliano de Souza e Oliveira de nomear o Ajudante Manuel José de Melo "para alistar e comandar o Corpo de Libertos que se deve organizar" naquela província meridional. Dizia que o governo "convidará os libertos a alistarem-se, e o Ajudante poderá recrutar aqueles de que tiver conhecimento, afim de que logo

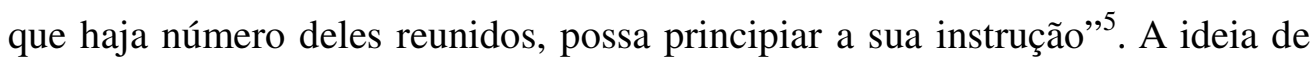
criação deste Corpo de Libertos se dava no contexto de apreensão pósindependência formal, em que se buscava a estruturação de uma defesa

\footnotetext{
${ }^{4}$ Assinam o documento o presidente da Junta, Jacinto Jorge dos Santos Correa, o secretário José dos Santos Mafra, Francisco Luís do Livramento e Joaquim de Santa Ana Campos. Pela mesma época, também fazia parte da Junta de Santa Catarina João de Bitencourt Pereira Machado e Souza (Arquivo Nacional, 1973, p. 1213).

5 Arquivo Público do Estado de Santa Catarina (Doravante APESC). Registro de correspondências recebidas pelos Comandantes/Governadores das Armas. Vol. 1. 1822-1827. 23/10/1822, fl. 7v-8.
} 
principalmente contra tropas estacionadas em Montevidéu, "que é de onde poderíamos recear mais próxima invasão"6.

Os padrões militares do período colonial, que em boa medida foram reproduzidos no Império brasileiro, possuíam parâmetros definidos quanto à cor de seus integrantes, tanto para as tropas de $1^{\text {a }}$ linha - profissionais -, quanto para as de $2^{\text {a }}$ linha - Milícias -, que eram formadas por parcelas civis da população. A despeito da visão deturpada de recenseadores do século XIX, que utilizavam classificações ligadas a suas discriminações tanto raciais como sociais, até 1837 as tropas de $1^{\text {a }}$ linha eram formadas majoritariamente por indivíduos brancos, aceitando pardos em alguns momentos e rejeitando os pretos (KRAAY, 2015, p. 46; IZECKSOHN, 2014, p. 96; BEATTIE, 2009, p. 54). Estes padrões discriminatórios de recrutamento teriam moldado "profundamente a experiência e a identidade dos militares e influenciaram a política racial durante essas décadas” (KRAAY, 2015, p. 46-47).

No caso específico do Corpo de Libertos a ser organizado em Santa Catarina, não se explicitava para qual linha deveriam ser remetidos os sujeitos que se apresentassem ou fossem recrutados para o serviço militar. Da mesma forma, a definição específica da cor dos seus integrantes permanecia em silêncio, sobrepujada pela categoria genérica dos libertos. Em um momento de agitação política e militar e o receio de um ataque português para a recolonização do Brasil, os padrões de cor nas forças armadas poderiam ser relegados? A $1^{\mathrm{a}}$ linha poderia ser o local de pretos, neste contexto? Vejamos.

No mês seguinte às ordens para a organização do Corpo de Libertos, a Junta Provisória escreveu para o Comandante das Armas nos seguintes termos:

Por efeito de equívoco na inteligência de uma ordem, consta agora a esta Junta do Governo que o preto forro Manoel dos Santos, morador na Enseada de Brito, fora pelo Ajudante de ordens deste governo remetido ao de V. $\mathrm{S}^{\mathrm{a}}$. para lhe assentar praça em um dos corpos de primeira linha [...]. não é da intenção do mesmo governo que ele seja empregado no serviço em que se acha: portanto, sirva-se V. $S^{\text {a }}$. de lhe

\footnotetext{
${ }^{6}$ APESC. Registro de correspondências recebidas pelos Comandantes/Governadores das Armas. Vol. 1. 1822-1827. 23/10/1822, fl. 7-7v. Apesar de ser da mesma data e trocado entre as mesmas autoridades, trata-se de ofício diferente do supracitado.
} 
mandar dar baixa e escusa do referido serviço, afim de que possa recolher-se à sua casa, devendo todavia ficar alistado no Corpo de Libertos. ${ }^{7}$ (grifo meu)

O documento é bastante claro: o preto forro Manuel dos Santos não deveria mais sentar praça na $1^{\mathrm{a}}$ linha do exército, à qual por engano havia sido incorporado. Sendo enviado para casa, ficaria alistado no Corpo de Libertos. Foi o fato de Manoel ser considerado preto que fez com que a Junta deliberasse pela sua exclusão da $1^{\mathrm{a}}$ linha e pelo seu alistamento no Corpo de Libertos. As discriminações raciais e sociais, desta forma, teriam sido mais importantes que a relevância de um soldado em armas em um momento político conturbado mas, diga-se de passagem, sem ameaça imediata de invasão. Por esta passagem também é possível inferir que o Corpo de Libertos seja de $2^{\text {a }}$ linha, ou seja, ligado às milícias.

As maneiras pelas quais um sujeito podia ser conhecido no referente à sua identidade ou designação racial - aquilo que pode ser chamado de fenótipo racial - podia variar muito, dependendo de caso para caso. Preto, pardo, mulato, moreno, cabra: estas e outras designações "dependiam tanto do contexto físico, social e econômico quanto do indivíduo". De acordo com Russel-Wood, "para determinar a posição de uma pessoa, mesmo exclusivamente dentro dos parâmetros estreitos da raça, era essencial levar em conta fatores adicionais de grau variável de tangibilidade: riqueza, posição social, comportamento". Esta classificação, ao mesmo tempo em que era bastante variável, era fator importante para a identificação do indivíduo na sociedade, pois "a norma ou imagem somática seria um fator importantíssimo não só da avaliação da identidade racial como também da determinação do potencial de mobilidade de alguém” (RUSSEL-WOOD, 2005, p. 47-49). Ou seja, ser reconhecido como preto, pardo, mulato, etc., apontava para posições sociais que comportavam horizontes de expectativa possíveis e que eram naturalmente alargados em momentos de agitação política, como à época da independência.

\footnotetext{
7 APESC. Registro de correspondências recebidas pelos Comandantes/Governadores das Armas. Vol. 1. 1822-1827. 16/11/1822, fl. 24v.
} 
Se os parâmetros de Russell-Wood são referentes ao período colonial brasileiro, as estruturas escravistas que permaneceram até o período da independência, embora frequentemente redefinidas por ações negras, em boa medida não foram modificadas. As formas de se referir ao fenótipo racial permaneciam com poucas alterações. A categoria "pardo", por exemplo, "é típica do final do período colonial e tem uma significação muito mais abrangente do que a noção de 'mulato' (este, sim, um termo de época diretamente ligado à mestiçagem) ou mestiço que muitas vezes lhe é associada". Por sua vez, "durante todo o período colonial, e mesmo até bem avançado o século XIX, os termos 'negro' e 'preto' foram usados exclusivamente para designar escravos e forros". Segundo Hebe Mattos, a categoria "pardo" foi inicialmente utilizada

para designar a cor mais clara de alguns escravos,
especialmente sinalizando para a ascendência europeia de
alguns deles, mas ampliou sua significação quando se teve
que dar conta de uma crescente população para a qual não
mais era cabível a classificação de "preto" ou de "crioulo",
na medida em que estas tendiam a congelar socialmente a
condição de escravo ou ex-escravo. A emergência de uma
população livre de ascendência africana - não
necessariamente mestiça, mas necessariamente dissociada, já
por algumas gerações, da experiência mais direta do cativeiro
- consolidou a categoria "pardo livre" como condição
linguística necessária para expressar a nova realidade, sem
que recaísse sobre ela o estigma da escravidão, mas também
sem que se perdesse a memória dela e das restrições civis que
implicava (2000, p. 14-15).

Ao ter mente estes padrões de classificação, é possível compreender por quais parâmetros o "preto" Manoel foi retirado da $1^{\text {a }}$ linha e foi alistado no Corpo de Libertos.

Neste momento - entre 1822 e 1823 -, não parece relevante se Manoel era nascido no Brasil ou na África. Porém, a partir do ano seguinte, a via militar poderia ser ainda mais interessante caso ele não fosse crioulo. A Constituição de 1824 concedeu a cidadania a libertos que nasceram no Brasil, mas não tocou no tema dos africanos (MAMIGONIAN, 2015, p. 195). Nem escravos, nem 
estrangeiros, estes sujeitos tinham na projeção militar uma das poucas possibilidades de ascensão profissional e social.

Ao passo que seguia a busca por soldados para o Corpo de Libertos, em 18 de janeiro de 1823 a Junta Provisória informou ao Comandante das Armas que concordava com as proposições por ele trazidas acerca dos libertos alistados. Estes deveriam ser "agregados aos regimentos dos respectivos distritos, para serem disciplinados e regidos do modo que V. S. propõe”. O documento não deixa claro se seria criado em cada distrito uma seção do Corpo de Libertos ou - o que pelo contexto parece mais óbvio - eles seriam agregados aos regimentos de milícia já existentes. O presidente afirmava que no mesmo dia estavam sendo passadas "ordens aos comandantes de distritos para fazerem avisar e apresentar nesta vila capital no dia 26 deste mês [de janeiro] aos ditos libertos alistados, afim de que V. $\mathrm{S}^{\mathrm{a}}$. lhe passe a sua revista" ${ }^{\prime 8}$. Portanto, antes de adentrarem nos regimentos em seus distritos, os libertos deveriam se apresentar em Nossa Senhora do Desterro para a revista marcial por parte do Comandante das Armas. Ficar servindo em seus distritos era uma medida bastante profícua ao recrutamento. Não são poucas as demonstrações já dadas na historiografia (LUFT, 2013; MENDES, 2010; RIBEIRO, 2005) de que a arregimentação e deslocamento para outros locais que não as imediações do local de moradia, para além de prejudicial aos recrutados, pois lhes privava as atividades econômicas, também era bastante inócua ao recrutamento, uma vez que muitos indivíduos fugiam para os matos para não serem encontrados quando da passagem das partidas de recrutadores. Em seguida o presidente faz apontamentos sobre a questão racial envolvendo estes sujeitos:

E como tendo-se mandado proceder a recrutamento para a $1^{\mathrm{a}}$ linha, não se tem achado quase ninguém para recrutar fora dos corpos de $2^{\mathrm{a}}$ linha, [...] julga este governo a propósito que no ato da revista ordenada, V. $S^{a}$. faça assentar praça na $1^{\mathbf{a}}$ linha àqueles dos ditos libertos, sendo pardos, que se acharem próprios para isso, e que não tenha a seu favor as exceções que fazem as instruções de 10 de julho do ano

\footnotetext{
8 APESC. Registro de correspondências recebidas pelos Comandantes/Governadores das Armas. Vol. 1. 1822-1827. 18/01/1823, fl. 49-50.
} 
passado ${ }^{9}$, remetidas pela Secretaria de Estado dos Negócios da Guerra. ${ }^{10}$ (grifo meu)

As marchas constantes e o controle mais direto exercido sobre os integrantes dos corpos de $1^{\text {a }}$ linha faziam com que muitos indivíduos buscassem um alistamento nas milícias como forma de fugir do serviço no exército regular. Esta é a explicação para que fosse difícil encontrar sujeitos para a $1^{a}$ linha que não estivessem já ligados aos corpos milicianos, pois este os isentava de recrutamento para o exército profissional. A solução encontrada, portanto, passava por arregimentar na $1^{\text {a }}$ linha os sujeitos que haviam se apresentado ou sido recrutados para o Corpo de Libertos. Entretanto, nem todos, uma vez que apenas os pardos dentre os libertos estariam aptos a adentrar as fileiras da $1^{\mathrm{a}}$ linha.

Como já se apontou aqui, esta diferenciação vem dos padrões do Antigo Regime, no qual, a partir do século XVIII, "pardo" começou "a aparecer como uma identidade reivindicada: gente que queria se diferenciar do universo da escravidão, cobrar privilégios e tratamento específicos e, mesmo, constituir-se em corpo social específico" (LARA, 2007, p. 142), diferentemente de termos pejorativos como "mulato" - com o qual se assemelhavam na cor da pele - e dos "pretos". Mantinham-se, assim, também nas atividades castrenses os padrões de cor que perpassavam quase todos os tipos de relação no final do período colonial e, ao menos, nas primeiras décadas do Império. Para o caso de Santa Catarina, já se apontou que estes padrões de cor anteriores à racialização "científica" permaneceram até a segunda metade do século XIX, quando o indivíduo passou a ser discriminado "ora tendo por referência a cor, atributo da

\footnotetext{
${ }^{9}$ As instruções de 1822 dizem o seguinte no que se refere às isenções: "VI. São isentos do recrutamento os homens casados; o irmão de órfãos, que tiver a seu cargo a subsistência, e educação deles: o filho único de lavrador, ou um a sua escolha, quando houver mais de um, cultivando terras ou próprias, ou aforadas, ou arrendadas. VII. O artigo acima se estende do mesmo modo ao filho uni co de viúvas. VIII. São também, isentos, o feitor, ou administrador de fazendas com mais de seis escravos, ou plantação, ou de criação, ou de olaria. IX. Os tropeiros, boiadeiros, os mestres de ofícios com loja aberta, pedreiros, carpinteiros, canteiros, pescadores de qual discrição, uma vez que exercitem os seus ofícios respectivamente e tenham bom comportamento.” BRASIL. Decisões do Governo no 67 - GUERRA - Em 10 de julho de 1822. Biblioteca da Câmara dos Deputados. Brasília. Distrito Federal. Disponível em: http://www2.camara.gov.br. Acesso em abril de 2020.

10 APESC. Registro de correspondências recebidas pelos Comandantes/Governadores das Armas. Vol. 1. 1822-1827. 18/01/1823, fl. 49-50.
} 
raça (preto, mulato), ora pelas antigas classificações definidas pela ascendência/origem (preto, pardo, crioulo, africano), acompanhado da condição (livre, liberto, cativo)" (CARDOSO, 2004, p. 254-255). A partir de então um novo modo de hierarquização e novas maneiras de exclusão foram colocadas em prática, dentro de um projeto pensado em nível internacional, mesmo que chegadas de forma já atrasada ao Brasil, como demonstrado por Lilia Schwarcz (1993, cap. 2).

Voltando ao caso em análise, os indícios indicam que foi abortado o projeto de haver um Corpo específico de libertos para garantir a independência em Santa Catarina, sendo seus membros dispersados nos batalhões milicianos de seus distritos ou alistados na $1^{\mathrm{a}}$ linha. As autoridades se anteciparam a possíveis desentendimentos com os proprietários de escravos, como os que ocorreram em outros locais do nascente Império, como na Bahia. Nesta província, o general francês Pedro Labatut (1776-1849) projetou a criação de um Batalhão de Libertos Constitucionais e Independentes do Imperador no ano de 1822, constituído por pardos e pretos forros. Inicialmente, Labatut não tencionava recrutar escravos, mas apenas os libertos. Na sequência dos acontecimentos, foi sugerida uma contribuição voluntária de escravos por parte dos senhores de engenho. A proposta não foi aceita pelo Conselho Interino, e as atitudes de Labatut foram consideradas "profundamente perturbadoras, não somente devido à ameaça que o recrutamento de escravos constituía à propriedade e à grande lavoura, mas também porque elas tocavam na delicada questão racial” (KRAAY, 2015, p. 195). Não sendo aceita pelas autoridades, na prática a proposta causou um aumento significativo no número de fugas de escravos, que se apresentavam para lutar pela independência na esperança de ganhar a alforria ao fim das agitações, por mais que o alistamento representasse apenas uma promessa implícita de liberdade (KRAAY, 2002, p. 114). Por fim, o governo imperial se viu obrigado a mandar "libertar todos os escravos que serviram nas fileiras do exército brasileiro contra as tropas portuguesas, na luta 
da independência, na província da Bahia" ${ }^{\text {"11 }}$, não sem antes proteger o direito de propriedade e compensar os seus proprietários senhores de engenho. $\mathrm{Na}$ província meridional do Rio Grande do Sul, vizinha à Santa Catarina, por sua vez, as conturbações da independência levaram a uma ainda maior concentração de poder nas hostes milicianas e, pela primeira vez, homens de cor livres foram incorporados aos corpos de $2^{\mathrm{a}}$ linha naquela província, antes com presença apenas de brancos e indígenas. A criação de uma companhia de "homens pardos" em dezembro de 1822, para defender a capital daquela província, era bastante idiossincrática, pois "a companhia era formada por um total de 117 homens, dos quais 96 eram soldados" (Miranda, 2009, p. 169-170). Os desentendimentos e possíveis cisões entre as tropas regulares no tema da independência levaram a uma tentativa de enfraquecimento destas por parte do governo, e retirar indivíduos para as milícias fazia parte desta estratégia. Quanto a fugas de escravos para se apresentarem aos exércitos, nos faltam informações. Relevante é o fato de que o Rio Grande do Sul também não recebeu nenhum ataque direto buscando uma recolonização.

É possível inferir que a falta de um perigo imediato de combates com tropas portuguesas em Santa Catarina - como na Bahia, por exemplo - foi responsável pela não ocorrência de um recrutamento de escravos ou fugas regulares destes para o exército - assim como na Bahia antecipou a entrada de pretos nas tropas regulares (KRAAY, 2015). Porém, não se pode desconsiderar que os atores sociais responsáveis pelas atividades bélicas estivessem preocupados com as implicações que um provável alistamento acarretaria, e agissem para evitá-las. Não houve uma invasão portuguesa em Santa Catarina, mas os sujeitos contemporâneos envolvidos nos fatos não tinham conhecimento sobre o decorrer dos acontecimentos. Para eles, a equação entre os fatores segurança militar do território e da independência, com segurança racial e de propriedade, pendeu a enfraquecer políticas que agitassem as camadas que formavam a base da sociedade. Quando se pensou em utilizar a força da

\footnotetext{
${ }^{11}$ BRASIL. Decisões do Governo no 113 - GUERRA - Em 30 de julho de 1823. Biblioteca da Câmara dos Deputados. Brasília. Distrito Federal. Disponível em: http://www2.camara.gov.br. Acesso em abril de 2020.
} 
escravatura para as armas, em outubro de 1822, não foi aventada a possibilidade de que os cativos poderiam se apresentar em troca de liberdade, mas seriam levados pelos feitores das fazendas, e isso apenas "sendo praticável no momento preciso", quando se "estabelecerem os sinais de alarma [sic]"12. Mesmo assim, na primeira década do Império, pretos, pardos e escravos se aproveitaram das possibilidades trazidas pela via militar, principalmente pelas conturbações da Guerra da Cisplatina, e abriram espaços para a busca da liberdade, no caso dos escravos, ou para que fosse confirmada e cumprida a “inteira liberdade” para os libertos, como na expressão de Magda Ricci (1993, p. 203).

\section{Tentativa de melhores condições em tempos conflituosos}

Durante as diversas vezes em que Portugal e, posteriormente, o Brasil independente estiveram em guerra com o Império espanhol vizinho ou com as repúblicas que surgiram da sua dissolução, a utilização de escravos ou alforriados foi uma constante dentre as tropas envolvidas. Não como simples massas de manobra, estes indivíduos tinham "conhecimento da importância desta via para melhoria de condições sociais, para o alcance da alforria e, sobretudo, do caminho do serviço militar para a conquista de direitos civis" (CARVALHO, 2013, p. 101). Não apenas as tropas luso-brasileiras fizeram uso de escravos e libertos, mas também os exércitos das antigas colônias espanholas em território americano. Além do mais, "as fugas a partir do Brasil eram estimuladas por líderes políticos platinos, pois estes desejavam retirar braços do sistema produtivo rio-grandense e homens com potencial militar" (FERREIRA, 2010, p. 146-149). Algumas vezes, promessas eram feitas para que trocassem de lado nos conflitos, como quando o general Lecor, comandante das tropas luso-brasileiras durante a ocupação oriental de 1816/17, prometeu a liberdade aos escravos que estivessem engajados nas tropas rebeladas. Segundo Gabriel Aladrén, Lecor conseguiu "com este contingente e recrutando outros cativos

\footnotetext{
12 APESC. Registro de correspondências recebidas pelos Comandantes/Governadores das Armas. Vol. 1. 1822-1827. 19/10/1822. fl. 4-4v.
} 
através de compras e doações de senhores", formar "dois batalhões de caçadores libertos, nomeados $1^{\circ}$ e $2^{\circ}$ Batalhões de Libertos d'El Rey”. O $1^{\circ}$ Batalhão foi formado ainda em 1817 e contaria com 759 praças, entre soldados e oficiais. O $2^{\circ}$ Batalhão, por sua vez, foi criado no ano seguinte (ALADRÉN, 2009, p. 445-446; 2012, cap. 8).

$\mathrm{Na}$ província de Santa Catarina - como implicitamente se vem demonstrando -, durante as conturbações imediatas ao processo de independência brasileira, foi mantido um controle estrito sobre as camadas pardas e pretas da sociedade. Isto não significou, porém, que sujeitos considerados de cor não estivessem participando do exército e buscando nele espaços de liberdade. A deflagração da Guerra da Cisplatina (1825-1828) contribuiu para criar ambiente propício à utilização das vias militares para melhores condições de existência, e muito além da participação de escravos no corte de madeira e atividades ligadas à manutenção de embarcações que passavam em direção aos campos de batalha meridionais (BALDIN, 1979). Para demonstrar, entre outros exemplos existentes na documentação, foi escolhido um dos casos de sujeitos das camadas ditas de cor.

A existência de elementos considerados desajustados nas ruas, principalmente durante a noite, era um fato que chamava atenção das autoridades. Talvez por esta razão na noite de 13 de novembro de 1827 foi preso "por uma ronda da polícia, um preto por nome José Antônio". O fato de não haver na documentação uma explicação para o motivo da prisão reforça a ideia de que a razão tenha sido o simples fato de vagar sem uma finalidade aparente. Seja qual tenha sido a motivação para a ronda aprisionar o preto José Antônio, o fato é que "o Reverendo Capelão do Batalhão no 8 da $1^{\mathrm{a}}$ linha do exército, Caetano de Araújo Figueiredo Mendonça Furtado”, requereu diretamente ao presidente da província "a soltura, dizendo ser seu escravo José

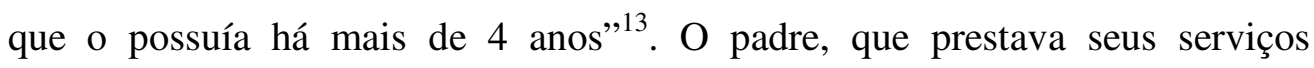
espirituais ao exército ainda em guerra contra as Províncias Unidas, estava se

\footnotetext{
13 APESC. Registro de correspondências recebidas pelos Comandantes/Governadores das Armas. Vol. 1. 1822-1827. 16/11/1827. fl. 181.
} 
sentindo prejudicado e querendo reaver uma propriedade que considerava sua por direito. Este, todavia, não era o entendimento do encarcerado José Antônio, pois ao passo que o reverendo o reclamava como seu, o

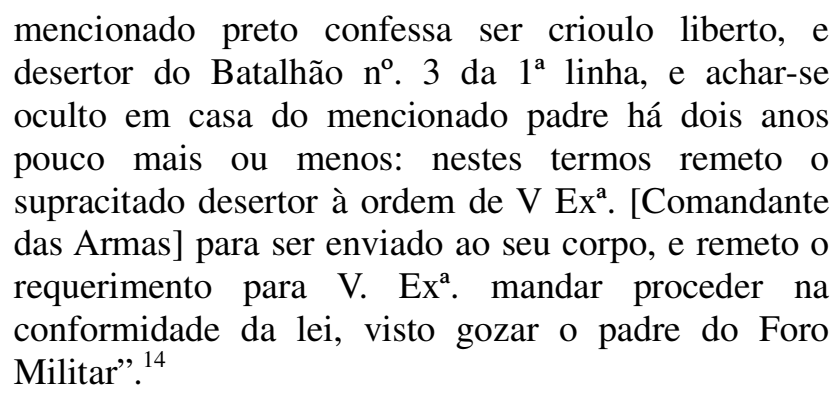

Relevante informar desde já que se desconhece até o momento qual dos indivíduos estava faltando com a verdade e mesmo qual tenha sido o desfecho desta história e o destino final de José Antônio. Entretanto, algumas considerações merecem ser feitas.

Se o preto José Antônio estivesse falando a verdade e de fato fosse soldado desertor do exército, isso significa que possuía uma relação muito boa com o reverendo, uma vez que permaneceu escondido em sua casa durante cerca de 2 anos. Esta ação teria permitido que José Antônio não fosse enviado para a guerra ao sul, contra as tropas platinas, uma vez que nos dois anos em que esteve escondido - ou seja, desde 1825 -, as atividades bélicas ficaram constantes na Banda Oriental. Possivelmente, o soldado teria preferido ficar prestando alguns serviços ao padre em troca da proteção, aguardando o final da guerra para um possível perdão aos desertores e uma reincorporação ao seu batalhão. O tempo em que permaneceu em esconderijo também serviria para pensar em alguma alternativa para garantir a sua posição social de homem livre ou liberto, que não o retorno à tropa. A sua prisão na noite de 13 de novembro de 1827 é, desta forma, entendida como um descuido seu, em um dos poucos momentos em que o desertor se permitia aparecer em público. Pode-se também imaginar a surpresa de José Antônio quando soube das intenções do reverendo

\footnotetext{
14 APESC. Registro de correspondências recebidas pelos Comandantes/Governadores das Armas. Vol. 1. 1822-1827. 16/11/1827. fl. 181.
} 
de tê-lo como seu escravo e perceber que as intenções do religioso não eram tão bondosas e desinteressadas.

A outra versão dos fatos - a do padre - traz conclusões diferentes. Sendo reverendo do exército, ele permanecia longos períodos longe de casa, onde deixava seu escravo. Esta condição daria oportunidade para o cativo desfrutar de uma maior frouxidão na rigidez que existiria caso o seu proprietário estivesse constantemente com ele. Poderia, inclusive, vagar durante as noites pela cidade. Sabendo do contexto belicoso existente ao sul do Império e da necessidade de soldados, José Antônio pode até, inclusive, ter criado alguma ocasião para ser preso. Assim, alegaria à polícia ser desertor do exército e para ele esperava ser transferido, fugindo assim da condição de cativo. Obviamente, diria pertencer a um batalhão diferente do qual seu proprietário prestava seus serviços religiosos; nesse caso, o $3^{\circ}$ Batalhão a qual se referia José Antônio, era provavelmente o de Caçadores, que tinha a Corte como lugar de parada geral, conforme a Lei que organizou o exército em $1824^{15}$. Com a atitude premeditada de José Antônio, quem teria sido pego de surpresa era o reverendo, seu proprietário, ao dar falta dele e ter conhecimento que José Antônio estava preso e possivelmente seria agregado ao exército.

Há também outras possibilidades bastante críveis: a de que a informação dada pelo reverendo Furtado de ser José Antônio seu escravo tenha sido uma forma de não ser punido por dar auxílio a um desertor ${ }^{16}$; ou então, que no próprio dia a dia José Antônio aceitasse viver como se fosse escravo do reverendo, para ter proteção contra o recrutamento. Já foi apontado para outras regiões, que se passar por escravo de alguém poderia diminuir a chance de um indivíduo ser recrutado como soldado. De forma contraditória, "esta poderia ser mais uma maneira de se viver e fazer "cumprir a inteira liberdade"” (RICCI,

\footnotetext{
${ }^{15}$ Decreto de $1^{\circ}$ de dezembro de 1824 - Dá organização aos corpos de $1^{\mathrm{a}}$ e $2^{\mathrm{a}}$ linha do exército. In: Collecção das leis do Imperio do Brazil de 1824. Rio de Janeiro: Imprensa Nacional, 1886, p. 87-95.

${ }^{16}$ Talvez daí tenha resultado o desligamento do padre das atividades no exército por decreto de 10 de outubro de 1828. Arquivo Histórico do Exército. Tomo 73, Santa Catarina, 1820-1829. 21/10/1828, fl. 246.
} 
1993, p. 198-200). Ao fingir ser escravo, o sujeito poderia ter melhor condições de vida e desfrutar de forma mais completa a sua autonomia.

O episódio trouxe tanta dúvida entre as autoridades provinciais que chegou a subir ao conhecimento do Ministro da Guerra na Corte, que se limitou a mandar ser informado do que as averiguações concluíssem ${ }^{17}$. Seja como for, é possível afirmar que José Antônio foi um dos tantos casos registrados de pessoas pretas ou pardas - sob o jugo direto da escravidão ou não - que se cansaram de esperar e de acreditar em soluções constitucionais que poderiam ameaçar "as antigas regras costumeiras que sustentavam princípios de autoridade" (RICCI, 1993, p. 220) e que trouxessem mudanças significativas para suas condições de existência. Mais do que isso, o caso demonstra as inúmeras variáveis que estavam agindo sobre a estrutura escravista e ajuda a vislumbrar a hierarquia social oitocentista.

Agir poderia mudar a experiência de vida dos sujeitos, mas todas as ações deveriam ser bem deliberadas. Os momentos de agitação bélica eram os mais propícios para as apresentações aos exércitos, e se tornar soldado seguramente

não era o ideal de vida almejado por eles, e nem o exército constituía um ambiente minimamente agradável, mas para alguns pode ter sido a opção mais viável para suas vidas. Isso podia se dar, por exemplo, pela inserção em novas redes de relações ou pela mobilidade, através da ampliação das chances de sucesso na vida. Estar ou ter estado no exército podia thes conferir status diferenciado, e ainda, sentimentos como orgulho e honra (CARVALHO, 2013, p. 100).

Sendo ou não um desertor da $1^{\mathrm{a}}$ linha, o fato é que acabou para ela sendo remetido - ao menos a princípio -, o que informa que já ocorria uma mudança nas possibilidades de acesso de indivíduos considerados "pretos" a fileiras do exército profissional, talvez pela necessidade de soldados em momento de guerra efetiva e ameaçadora na fronteira próxima.

A opção de se tornar soldado ao invés de se manter escravo, esconde semelhanças entre as suas condições. A exemplo dos escravos de ganho, os

\footnotetext{
${ }^{17}$ Arquivo Histórico do Exército. Tomo 73, Santa Catarina, 1820-1829. 03/01/1828, fl. 227v.
} 
soldados também provinham seu sustento quando estavam de licença, usavam da deserção assim como os escravos utilizavam das fugas, e os indultos de deserção se assemelhavam aos perdões dos senhores aos escravos que retornassem voluntariamente. Todavia, "apesar destas similaridades estruturais, importantes diferenças na cor e na condição separava os soldados dos escravos; os soldados, na verdade, definiam importantes partes da sua identidade distinguindo-se dos escravos", e até mesmo afirmavam de forma grosseira a sua superioridade social ao "intimidar os escravos que estavam fora da supervisão direta de seus donos" (KRAAY, 2015, p. 125). A cor não deixou de ser, porém, um relevante diferencial entre soldados e escravos.

\section{Conclusão}

As mudanças políticas ocorridas a partir de 1831 viriam a modificar de uma vez por todas a conjuntura militar brasileira. A regência diminuiu a menos da metade o número do exército de $1^{\text {a }}$ linha (Sodré, 1979, p. 130), extinguiu as Milícias e as Ordenanças e criou a Guarda Nacional ${ }^{18}$, instituição que responderia ao Ministério da Justiça, e não mais à pasta da Guerra, como as antigas corporações extintas. $\mathrm{O}$ objetivo era diminuir o número e o poder de oficiais portugueses que ainda faziam parte do corpo do exército, além de descentralizar as operações a partir da Guarda Nacional. Na nova instituição não haviam barreiras raciais explícitas à interação entre os guardas, o que a levou até a ser considerada como uma primeira experiência de democracia racial ligada à militarização no Brasil (FARIA, 1977), mas que na prática não deixou de sentir a existência de barreiras raciais informais entre os integrantes (RIBEIRO, 2005). Em teoria, porém, os considerados pretos alistados na Guarda Nacional estavam autorizados a servir ombro a ombro com brancos, desde que atendessem aos requisitos censitários.

A prática de participação negra nas forças militares na América ibérica e nos países que surgiram dela, remonta ao período colonial, e está intimamente

\footnotetext{
${ }^{18}$ BRASIL. Lei de 18 de agosto de 1831. Biblioteca da Câmara dos Deputados. Brasília. Distrito Federal. Disponível em: http://www2.camara.leg.br/legin/fed/lei_sn/1824-1899/lei37497-18-agosto-1831-564307-publicacaooriginal-88297-pl.html. Acesso em abril de 2020.
} 
ligada à dissociação existente entre portar armas e gozar de ampla liberdade individual. Ao contrário dos aldeamentos puritanos da Nova Inglaterra, no "ambiente luso-brasileiro estar armado só garantia direitos por associação a notabilidades locais, conferindo muito pouco em termos de autonomia individual àqueles indivíduos mobilizados para a defesa dos interesses imediatos de seus senhores (IZECKSOHN, 2014b, p. 487)”. Esta condição permitia que aqueles com poder para o recrutamento - capitães das armas e câmaras municipais, que na maioria das vezes também eram senhores de escravos - e que compartilhavam da ideologia do patriarcado (KRAAY, 2015, p. 125), armassem até mesmo escravos nos momentos de necessidade, sem que isso significasse mudança na posição social dos cativos.

As esperanças constitucionais que permitiram com que escravos, libertos ou pretos e pardos livres pudessem esperar mudanças, também serviram para que os grupos que se sentiram ameaçados em privilégios reagissem, mesmo no início do período regencial. Por exemplo, em outubro de 1831 a Sociedade Patriótica de Desterro ${ }^{19}$, que reuniu importantes figuras da política provincial, "aprovou uma representação do sr. Carlos Maria Duarte Silva ${ }^{20}$, pedindo providências ao juiz de paz para que não consentisse que alguns estrangeiros e cativos usassem o laço nacional nos seus chapéus". Na mesma reunião, Jerônimo Coelho apresentou projeto para que "se criasse uma Guarda Municipal e se fizesse exercitá-la, entre outras razões por constar a existência de reuniões de negros em certa casa, 'a ponto de se exercitarem na maneira das armas". O projeto foi aprovado por unanimidade pelos demais membros da Sociedade e o presidente provincial disse que logo avisaria o juiz de paz para dar cumprimento às medidas (CABRAL, 1979, p. 386-387). Demarcaria-se, assim, à vista de todos, a diferença entre o mundo dos livres e dos cativos. Esta

\footnotetext{
${ }^{19}$ A Sociedade Patriótica era uma organização sem ligação formal com o governo, mas "da qual participava um número considerável de deputados da Assembleia Legislativa” da província. Influenciou diretamente as ações políticas provinciais e se converteu "numa força da política local, representando os interesses de um grupo que formará o Partido Liberal". Existiu de 1831 a 1836 (GARCIA, 2006, p. 106-107).

${ }^{20}$ Carlos Maria Duarte Silva nasceu em Montevidéu em 1806 e mudou-se para Desterro, onde faleceu em 1852. Foi deputado da Assembleia Legislativa provincial da $4^{a}$ a $7^{a}$ legislatura (PIAZZA, 1985, p. 206).
} 
ação era coerente com as recorrentes discussões sobre a cidadania em 1823, nas quais ficou claro o entendimento de que a melhor forma de garantir a manutenção da ordem social era pela integração do liberto na condição de cidadão (SLEMIAN, 2006, p. 846), não obstante a Constituição do ano seguinte ter excluído os africanos. Os libertos, inseridos em um mundo diferente dos escravos, precisavam criar espaços de atuação nos quais poderiam agir para buscar posições melhores. Assim, a busca pela cidadania e o entendimento de seus diferentes significados (MATTOS, 2005, p. 44-45) pode ser a chave de interpretação da ação de pessoas de cor livres e escravizadas nos primórdios do Estado brasileiro, animando muitos dos interessados.

Ao se prender às experiências de cativos e libertos na sociedade em transformação, é necessário atentar para a existência de sentidos vernáculos de liberdade - assim como identificado para Cuba e Luisiana, por Rebecca Scott (2006, p. 344-345) - e que é nascido da experiência de reclamar direitos. A partir destas experiências específicas em cada sociedade, que formaram os horizontes de possibilidade, surgiram diferentes graus de liberdade para pessoas de ascendência africana.

\section{Referências}

ALADRÉN, Gabriel. Experiências de liberdade em tempos de guerra: escravos e libertos nas Guerras Cisplatinas (1811-1828). Estudos Históricos, Rio de Janeiro, vol. 22, n. 44, 2009.

ALADRÉN, Gabriel. Sem respeitar fé nem tratados: escravidão e guerra na formação histórica da fronteira sul do Brasil (Rio Grande de São Pedro, c. 1777-1835). Tese (Doutorado em História) - PPGH/UFF, Niterói, 2012.

Arquivo Nacional. As Juntas Governativas e a Independência, vol. 3. Rio de Janeiro: Arquivo Nacional, 1973.

APESC. Registro de correspondências recebidas pelos Comandantes/Governadores das Armas. 1822-1834, 3 v., GA, local 30.

Arquivo Histórico do Exército. Rio de Janeiro. Tomo 73, Santa Catarina, 18201829. 
BALDIN, Nelma. A Intendência da Marinha de Santa Catarina e seu papel na ocupação da Província Cisplatina - (1817-1832). Dissertação (Mestrado em História) - PPGH/UFSC, Florianópolis, 1979.

BEATTIE, Peter M. Tributo de sangue: exército, honra, raça e nação no Brasil, 1864-1945. São Paulo: EDUSP, 2009.

BRASIL. Decisões do Governo no 67 - GUERRA - Em 10 de julho de 1822. Biblioteca da Câmara dos Deputados. Brasília. Distrito Federal. Disponível em: http://www2.camara.gov.br. Acesso em abril de 2020.

BRASIL. Decisões do Governo no 113 - GUERRA - Em 30 de julho de 1823. Biblioteca da Câmara dos Deputados. Brasília. Distrito Federal. Disponível em: http://www2.camara.gov.br. Acesso em abril de 2020.

BRASIL. Lei de 18 de agosto de 1831. Biblioteca da Câmara dos Deputados. Brasília. Distrito Federal. Disponível em: http://www2.camara.leg.br/legin/fed/lei_sn/1824-1899/lei-37497-18-agosto1831-564307-publicacaooriginal-88297-pl.html. Acesso em abril de 2020.

DECRETO de $1^{\circ}$ de dezembro de 1824 - Dá organização aos corpos de $1^{\mathrm{a}}$ e $2^{\mathrm{a}}$ linha do exército. In: Collecção das leis do Imperio do Brazil de 1824. Rio de Janeiro: Imprensa Nacional, 1886.

CABRAL, Oswaldo Rodrigues. Nossa Senhora do Desterro, Memória, vol. 2. Florianópolis: Lunardelli, 1979.

CARDOSO, Paulino de Jesus Francisco. Negros em Desterro: Experiências de populações de origem africana em Florianópolis na segunda metade do século XIX. Itajaí: CasAberta, 2004.

CARDOSO, Vitor Hugo Bastos. As dinâmicas político-territoriais de uma comunidade periférica no sul da América portuguesa: a Ilha de Santa Catarina e seu continente, 1680-1750. Dissertação (Mestrado em História) PPGH/UFSC, Florianópolis, 2013.

CARVALHO, Daniela Vallandro de. Fronteiras da Liberdade: experiências escravas de recrutamento, guerra e escravidão: Rio Grande de São Pedro, 
c.1835-1850. Tese (Doutorado em História) - PPGHIS/UFRJ, Rio de Janeiro, 2013.

CASTRO, Celso; IZECKSOHN, Vitor; KRAAY, Hendrik. Da história militar a "nova" história militar. In: CASTRO, Celso; IZECKSOHN, Vitor \& KRAAY, Hendrik (Orgs.). Nova História militar brasileira. Rio de Janeiro: FGV, 2004. DUARTE, Paulo de Queiroz. Lecor e a Cisplatina, 1816-1828. Vol. 1. Rio de Janeiro: Biblioteca do Exército, 1985.

FARIA, Maria Auxiliadora. A Guarda Nacional em Minas, (1831-1873). Dissertação (Mestrado em História) - UFPR, Curitiba, 1977.

FERREIRA, Fábio. A participação de índios e negros no exército português: o caso da Cisplatina. In: TAVARES, Célia Cristina da Silva; RIBAS, Rogério de Oliveira. Hierarquias, raça e mobilidade social: Portugal, Brasil e o Império colonial português (séculos XVI-XVIII). Rio de Janeiro: Contra Capa/Companhia das Índias, 2010.

FERREIRA, Gabriela. Conflitos no Rio da Prata. In: GRINBERG, Keila; SALLES, Ricardo (Orgs.). O Brasil Imperial, 1808-1831, vol. 1. Rio de Janeiro: Civilização Brasileira, 2011.

GARCIA, Carla Laner. Emanações perniciosas, moralidade corrosiva: os desdobramentos do discurso científico o centro urbano de Nossa Senhora do Desterro (1831-1864). Dissertação (Mestrado em História) - PPGH/UFSC, Florianópolis, 2006.

GOMES, Luciano Costa. Livres, libertos e escravos na história da população de Santa Catarina, 1787-1836. Revista brasileira de Estudos de População, Belo Horizonte, v.34, n.3, set./dez. 2017.

GRINBERG, Keila. O fiador dos brasileiros: cidadania, escravidão e Direito Civil no tempo de Antônio Pereira Rebouças. Rio de Janeiro: Civilização Brasileira, 2002.

IZECKSOHN, Vitor. Ordenanças, tropas de linha e auxiliares: mapeando os espaços militares luso-brasileiros. In: FRAGOSO, João; GOUVÊA, Maria de Fátima (Orgs.). O Brasil Colonial, vol. 3. Rio de Janeiro: Civilização Brasileira, 2014b. 
IZECKSOHN, Vitor. Slavery and war in the Americas: race, citizenship, and state building in the United States and Brazil, 1861-1870. Virginia: University of Virginia Press, 2014.

KRAAY, Hendrik. "Em outra coisa não falavam os pardos, cabras, e crioulos": o "recrutamento" de escravos na guerra de independência na Bahia. Revista Brasileira de História, São Paulo, v. 22, nº 43, 2002.

KRAAY, Hendrik. Política racial, Estado e Forças Armadas na época da independência, (Bahia, 1790-1850). São Paulo: Hucitec Editora, 2015.

KÜHN, Fábio. Gente da fronteira: família, sociedade e poder no sul da América Portuguesa - século XVIII. Tese (Doutorado em História) PPGH/Universidade Federal Fluminense, Niterói, 2006.

LARA, Silvia Hunold. Fragmentos setecentistas: escravidão, cultura e poder na América portuguesa. São Paulo: Companhia das Letras, 2007.

LEVI, Giovanni. A Herança Imaterial: trajetória de um exorcista no Piemonte do século XVII. Rio de Janeiro: Civilização Brasileira, 2000.

LUFT, Marcos Vinícios. “Essa guerra desgraçada”: recrutamento militar para a Guerra da Cisplatina (1825-1828). Dissertação (Mestrado em História) PPGH/UFRGS, Porto Alegre, 2013.

MAMIGONIAN, Beatriz Gallotti. Africanos livres: a abolição do tráfico de escravos no Brasil. São Paulo: Companhia das Letras, 2017.

MAMIGONIAN, Beatriz Gallotti. Os direitos dos libertos africanos no Brasil oitocentista: entre razões de direito e considerações políticas. História (São Paulo), v.34, n.2, 2015.

MATTOS, Hebe Maria. Escravidão e cidadania no Brasil monárquico. $2^{\mathrm{a}} \mathrm{ed}$. Rio de Janeiro: Jorge Zahar Ed, 2000.

MATTOS, Hebe. Prefácio. In: COOPER, Fredrik; HOLT, Thomas Cleveland; SCOTT, Rebecca Jarvis. Além da escravidão: investigações sobre raça, trabalho e cidadania em sociedades pós-emancipação. Rio de Janeiro: Civilização Brasileira, 2005.

MENDES, Fábio Faria. Recrutamento militar e construção do Estado no Brasil imperial. Belo Horizonte: Argvmentvm, 2010. 
MIRANDA, Marcia Eckert. A estalagem e o Império: crise do Antigo Regime, fiscalidade e fronteira na Província de São Pedro (1808-1831). São Paulo: Hucitec, 2009.

MORELLI, Federica. Race, Wars, and Citizenship: Free People of Color in the Spanish American Independence. Journal of the History of Ideas, v. 79, n. 1, 2018.

MUGGe, Miquéias Henrique. Prontos a contribuir: guardas nacionais, hierarquias sociais e cidadania (Rio Grande do Sul - século XIX). São Leopoldo: Oikos; Editora Unisinos, 2012.

NEVES, Lúcia Bastos Pereira das. Estado e Política na independência. In: GRINBERG, Keila; SALLES, Ricardo (Orgs.). O Brasil Imperial, 1808-1831, vol. 1. Rio de Janeiro: Civilização Brasileira, 2011.

NOGUEIRA, Shirley M. S. “A soldadesca desenfreada”: politização militar no Grão-Pará da Era da Independência (1790-1850). Tese (Doutorado em História) - PPGH/UFBA, Salvador, 2009.

PIAZZA, Walter. Dicionário Político Catarinense. Florianópolis: Assembleia Legislativa do Estado de Santa Catarina, 1985.

RIBEIRO, José Iran. Apresentar armas! Considerações historiográficas, metodológicas e empíricas sobre a redução de escala na pesquisa em História Militar. In: MARTINS, Maria Cristina Bohn; MOREIRA, Paulo Roberto Staudt. (Orgs.). Uma História em escalas: a microanálise e a historiografia latino-americana. São Leopoldo: Oikos; Unisinos, 2012.

RIBEIRO, José Iran. O Império e as revoltas: Estado e nação nas trajetórias dos militares do Exército imperial no contexto da Guerra dos Farrapos. Rio de Janeiro: Arquivo Nacional, 2013.

RIBEIRO, José Iran. Quando o serviço os chamava: milicianos e Guarda Nacional no Rio Grande do Sul (1825-1845). Santa Maria: Editora da UFSM, 2005.

RICCI, Magda Maria de Oliveira. "Nas fronteiras da independência”: um estudo sobre os significados da liberdade na região de Itu (1779-1822). Dissertação (Mestrado em História) - UNICAMP, Campinas, 1993. 
RODRÍGUEZ, Jaime E. La independencia de la América Española. Ciudad de México: Fondo de Cultura Económica, 2005.

RUSSELL-WOOD, Anthony John. Escravos e libertos no Brasil Colônia. Rio de Janeiro: Civilização Brasileira, 2005.

SCHWARCZ, Lilian Moritz. O Espetáculo das raças. Cientistas, instituições e questão racial no Brasil do século XIX. São Paulo: Companhia das Letras, 1993.

SCOTT, Rebecca Jarvis. Grados de Libertad: Cuba e Luisiana después de la esclavitud. Habana: Editorial de Ciencias Sociales, 2006.

SLEMIAN, Andrea. "Seriam todos cidadãos? Os impasses na construção da cidadania nos primórdios do constitucionalismo no Brasil (1823 - 1824)”. In: JANCSÓ, István (org.). Independência: História e historiografia. São Paulo: Editora HUCITEC; FAPESP, 2006.

SLEMIAN, Andrea. Sob o Império das Leis: Constituição e unidade nacional na formação do Brasil (1822-1834). Tese (Doutorado em História). PPGHIS/USP, São Paulo, 2006b.

SODRÉ, Nelson Werneck. A História Militar do Brasil. Rio de Janeiro: Civilização Brasileira, 1979.

THOMPSON, Edward. Palmer. Senhores e caçadores: a origem da lei negra. Rio de Janeiro: Paz e Terra, 1987.

Recebido em: 24 de abril de 2020 Aceito em: 24 de junho de 2021 